\title{
Inclusão profissional de pessoas com deficiência física em um serviço de saúde do Estado de Pernambuco*
}

\section{Professional inclusion of people with physical disability in a health facility in the state of Pernambuco}

\author{
Priscylla Emanuella Cavalcanti Pereira ${ }^{1}$, Ada Salvetti Cavalcanti ${ }^{2}$, \\ Ana Karina Pessoa da Silva Cabral ${ }^{3}$
}

http://dx.doi.org/10.11606/issn.2238-6149.v27i2p146-155

Pereira PEC, Cavalcanti AS, Cabral AKPS. Inclusão profissional com deficiência física em um serviço de saúde do Estado de Pernambuco. Rev Ter Ocup Univ São Paulo. 2016 maio-ago.;27(2):146-55.

RESUMO: No Brasil, estima-se que 45,6 milhões de pessoas têm algum tipo de deficiência. Porém, grande parte destas pessoas não tem acesso ao mercado trabalho ou, quando inseridas nos postos de trabalho, encontram dificuldades, por falta de preparo da empresa, baixa escolaridade e falta de capacitação profissional. O objetivo dessa pesquisa foi investigar a inclusão laboral de trabalhadores com deficiência física (TCDF) em um serviço de saúde no Estado de Pernambuco. Trata-se de um estudo transversal de abordagem qualitativa. Foram identificadas 4 (quatro) funções ocupadas pelos 9 (nove) TCDF, sendo elas: maqueiro, auxiliar de recepção e portaria, almoxarife de nutrição e técnico de enfermagem. Observou-se uma associação e restrição das tarefas com os tipos de deficiência, em todas as funções estudadas. Conclui-se que, apesar de complexo, o processo de inclusão deve considerar as habilidades reais das pessoas com deficiência, contribuindo com isto para uma sociedade mais equitativa e inclusiva.

DESCRITORES: Pessoa com deficiência; Trabalho; Terapia ocupacional; Brasil.
Pereira PEC, Cavalcanti AS, Cabral AKPS. Professional inclusion of people with physical disability in a health facility in the state of Pernambuco. Rev Ter Ocup Univ São Paulo. 2016 May-Aug.;27(2):146-55.

ABSTRACT: In Brazil, it is estimated that 45.6 million people have some kind of disability. However, most of these people have no access to the labor market or, when inserted in workstations, have difficulties due to lack of preparation of the company, poor education and lack of professional training. This study aims to investigate the labor inclusion of workers with disabilities in a health facility in the state of Pernambuco. This is a cross-sectional qualitative approach. We identified four roles occupied by the nine workes with disabilities, which are: stretcher-bearer, auxiliary reception and concierge, keeper of nutrition and nursing technician. It was observed that there was an association and restriction of tasks with the types of disabilities in all studied functions. It is concluded that although complex, the process of inclusion must consider the actual skills of the people with disabilities, contributing with a more equitable and inclusive society.

KEYWORDS: Disabled persons; Work; Occupational therapy; Brazil.

\footnotetext{
*Pesquisa referente ao Trabalho de Conclusão do Curso de Terapia Ocupacional da primeira autora, realizado na Universidade Federal de Pernambuco.

1. Terapeuta Ocupacional da Associação de Pais e Amigos dos Excepcionais (APAE) Camaragibe-PE. E-mail: pri.cavalcanti.to@gmail.com

2. Terapeuta Ocupacional do Instituto de Medicina Integral Prof. Fernando Figueira (IMIP) - Recife-PE. E-mail: adasc@hotmail.com

3. Terapeuta Ocupacional, Professora do Curso de Terapia Ocupacional da Universidade Federal de Pernambuco. E-mail: anakarinapessoa@yahoo.com.br

Endereço para correspondência: Ana Karina Pessoa da Silva Cabral. Departamento de Terapia Ocupacional, Universidade Federal de Pernambuco, Av. Jornalista Aníbal Fernandes, s/n, Cidade Universitária, Recife-PE. CEP 50740-560. E-mail: anakarinapessoa@yahoo.com.br
} 


\section{INTRODUÇÃO}

$\mathrm{D}$ e acordo com a Classificação Internacional de Funcionalidade, Incapacidade e Saúde CIF (2001), função do corpo são as funções fisiológicas dos sistemas orgânicos e as estruturas do corpo são partes anatômicas do corpo, tais como, órgãos, membros e seus componentes. Quando o indivíduo apresenta algum problema nestas áreas, define-se que ele tem uma deficiência seja ela transitória ou permanente, contudo, sua ocorrência não indica, necessariamente, a existência de dificuldades na realização de tarefas ou no envolvimento em situações da vida ${ }^{1}$.

Desse modo, considera-se pessoa com deficiência (PD) "aquela que tem impedimento de longo prazo de natureza física, mental, intelectual ou sensorial, o qual, em interação com uma ou mais barreiras, pode obstruir sua participação plena e efetiva na sociedade em igualdade de condições com as demais pessoas"2.

No Brasil, segundo dados do Censo 2010 do Instituto Brasileiro de Geografia e Estatística (IBGE), cerca de $23,91 \%$ da população, isto é, 45,6 milhões de pessoas têm algum tipo de deficiência. Esta diferença é ainda mais evidente na região Nordeste, onde a taxa chega a 30,97\%, provavelmente pela influência por agravantes como más condições sócio-econômicas, sanitárias e educacionais ${ }^{3}$.

Quanto aos tipos, as deficiências são categorizadas em: física, auditiva, visual, intelectual e múltipla. Neste estudo serão abordadas as PD física que são aquelas com alteração completa ou parcial de um ou mais segmentos do corpo humano, acarretando o comprometimento da função física ${ }^{4}$.

Grande parte das PD não está presente nas ruas, nas escolas comuns, nos locais de lazer e cultura e, muito menos têm acesso ao trabalho. Os problemas daí decorrentes se refletem na baixa escolaridade, na grande dificuldade de inserção social e na constituição de vínculos, além dos já estabelecidos nos núcleos familiares ${ }^{5}$.

Há algumas décadas, veem ocorrendo mudanças que apontam avanços neste processo, como o novo olhar acerca da PD, preconizado pela Organização Mundial de Saúde (OMS), por meio da CIF. A criação de leis como a n ${ }^{\circ} 7.853 / 89$ que assegura às $\mathrm{PD}$ o pleno exercício de seus direitos básicos e a Lei $n^{\circ} 8.213 / 91$, que além de preconizar os benefícios da Previdência Social, define que as empresas que possuem 100 ou mais empregados devem reservar uma cota de vagas para as PD (entre 2\% e 5\%, para empresa privada, conforme o porte da empresa, e para o serviço público de $5 \%$ a $20 \%$ ), representam iniciativas importantes para garantir a estes indivíduos o direito ao desempenho do papel ocupacional ${ }^{6}$.
Outra conquista em termos de legislação está na Lei complementar $\mathrm{n}^{\circ} 142$, de 15 de maio de 2014, que regulamenta a concessão de aposentadoria da PD no Regime Geral de Previdência Social. Para o reconhecimento do direito à aposentadoria, considera-se PD aquela que tem impedimentos de longo prazo de natureza física, mental, intelectual ou sensorial, os quais, em interação com diversas barreiras, podem obstruir sua participação plena e efetiva na sociedade em igualdade de condições com as demais pessoas?

Destaca-se também ações governamentais, como o programa "Viver sem limites", lançado em 2011, e que visa garantir que a Convenção Sobre a Pessoa com Deficiência, da ONU, aconteça de fato na vida das pessoas por meio de ações federais, estaduais e municipais melhorando o acesso à educação, inclusão social, atenção à saúde e acessibilidade ${ }^{8}$.

Dejours ${ }^{9}$ afirma que o trabalho é uma das dimensões principais na vida dos indivíduos. Pode ser fonte de saúde e instrumento de emancipação do sujeito, responder a uma série de necessidades, permitir a criação de um território sobre o qual pode se assentar o reconhecimento social, a integração social e constituir a identidade do indivíduo".

Contudo, verifica-se ainda que há poucas PD inseridas em atividades profissionais e no mercado formal. Ao mesmo tempo, quando as empresas contratam para cumprir a legislação, talvez pela falta de apoio e incentivo por parte do governo, acabam segregando o funcionário, sendo muitas vezes subutilizado, excluído ou sem conseguir se adaptar à função ${ }^{10}$.

A Terapia Ocupacional propõe a inclusão dos indivíduos no trabalho como objetivo primordial no processo de reabilitação. Segundo o Conselho Federal de Fisioterapia e Terapia Ocupacional ${ }^{11}$, fazem parte do rol de procedimentos deste profissional: treinamento para atividade laborativa, procedimentos relacionados à ergonomia, atividades de trabalho, bem como, avaliação do desempenho ocupacional, identificando habilidades e limitações do indivíduo, para a realização das Atividades da Vida Diária, Instrumentais de Vida Diária, Atividades Escolares e de Trabalho ${ }^{12}$.

Para identificação do desempenho do trabalhador no posto e das demandas do trabalho, o terapeuta ocupacional utiliza do método de análise ergonômica do trabalho bem como da técnica de análise da atividade humana. Pode assim verificar a adequação dos postos às habilidades dos trabalhadores para a realização das tarefas e, se necessário, propor melhorias ${ }^{12,13}$.

Diante da discussão atual acerca deste tema, da experiência de estágio no centro de reabilitação de uma instituição de saúde da cidade do Recife e da participação no seu programa de inclusão laboral, observou-se a necessidade de contribuir com a inclusão das PD no cenário laboral, a partir do conhecimento do seu perfil funcional e das demandas do posto de trabalho. Desta forma, este 
Pereira PEC, et al. Inclusão profissional de pessoas com deficiência física. Rev Ter Ocup Univ São Paulo. 2016 maio/ago.;27(2):146-55.

trabalho teve como objetivo investigar a inclusão laboral de trabalhadores com deficiência física (TCDF) em um serviço de saúde no Estado de Pernambuco.

\section{MÉTODO}

\section{Tipo do Estudo}

Trata-se de um estudo transversal de abordagem qualitativa. Os estudos transversais descrevem os indivíduos de uma população com relação às suas características pessoais e suas histórias de exposição a fatores causais suspeitos ${ }^{14}$. A investigação qualitativa busca elucidar valores, crenças, representações, hábitos, atitudes, percepções e opiniões ${ }^{15}$.

\section{Local do estudo}

O estudo foi realizado em um serviço de saúde que faz parte de um complexo hospitalar, centro de referência assistencial em diversas especialidades no Estado de Pernambuco, localizado na cidade do Recife - PE, Brasil. Caracteriza-se como uma instituição de caráter filantrópico, que atua nas áreas de assistência médico-social, ensino, pesquisa e extensão comunitária, oferecendo assistência integral a crianças, adolescentes, adultos e idosos.

Este trabalho está vinculado ao projeto de pesquisa "Perfil Biopsicossocial dos Funcionários com Deficiência", aprovado pelo Comitê de Ética em Pesquisa em Seres Humanos do Instituto de Medicina Integral Professor Fernando Figueira CEP-IMIP, em 19/07/2012, sob o número de protocolo 3045-12.

\section{Caracterização da amostra e procedimento de coleta dos dados}

Foram incluídos no estudo funcionários contratados com deficiência física que, durante o período de coleta, estavam desempenhando suas funções laborais no serviço; e supervisores, responsáveis diretos por estes trabalhadores; todos sob aceitação da participação na pesquisa através da assinatura do Termo de Consentimento Livre e Esclarecido (TCLE). Foram excluídos, aqueles sujeitos que estavam afastados para algum tipo de tratamento ou do posto de trabalho (férias ou licença), no período destinado à coleta de dados.

Dentre os mais de 33 setores existentes no serviço, 19 apresentavam pelo menos um TCDF, no entanto, destes, foram excluídos 10: quatro funcionários não trabalhavam mais na Instituição, um não foi localizado, três afastados para tratamento, um de licença maternidade e um estava de férias no período da coleta. Totalizou-se assim uma amostra de nove TCDF e oito supervisores, considerando que um destes supervisores estava responsável por dois trabalhadores.

Os dados foram coletados por meio de entrevista, utilizando roteiro semiestruturado, após agendamento com funcionários e supervisores, no início ou no final do turno de trabalho, de modo a não interferir na realização das tarefas. As entrevistas tiveram duração de aproximadamente 30 minutos, sendo registradas por meio de gravação e posteriormente transcritas. Para análise dos dados, foi utilizada a análise de conteúdo temático, sendo destacadas as categorias temáticas resultantes do processo de análise e, em seguida, descritas por aparição ${ }^{16}$.

\section{Variáveis}

As variáveis relacionadas à caracterização dos funcionários foram: Tipo e tempo da deficiência, tempo de ausência do mercado de trabalho, tempo de retorno as atividades laborais, tipo de tratamento realizado (Fisioterapia, Psicoterapia, Terapia Ocupacional e outros), função laboral desempenhada, mudança ou adequação da função atual em relação à anterior. Além disso, a descrição das atividades no ambiente de trabalho (operação de materiais, realização de atividades conjuntas, higiene, manipulação de objetos, equilíbrio, transferência, locomoção, comunicação e cognição).

As variáveis relacionadas aos supervisores foram: Descrição da Função, Rodízio, Tempo/Velocidade, Habilidades Necessárias, Adaptações/ Ajustes Especiais, Postura em relação à inserção dos TCDF contratados no setor e Postura em relação à inserção de novos TCDF, a serem contratados.

No tocante a caracterização da pessoa e tipo de deficiência, foram coletados dados por meio de roteiro de entrevista estruturado, utilizando o modelo de inclusão baseado na atividade de Simonelli et al. ${ }^{17}$ que propõe analisar as PD, suas potencialidades, conhecimentos, as barreiras e os facilitadores da execução de atividades; e os locais de trabalho, posturas exigidas pelas tarefas de trabalho, movimentos, requisitos técnicos e conhecimentos necessários.

Este modelo foi adaptado para atender às demandas desta pesquisa, limitando-se à análise do trabalho prescrito, devido a fatores como: diferença do público alvo no que diz respeito aos postos de trabalho, tempo de coleta dos dados, particularidades do serviço de saúde e tipos de tarefas desempenhadas.

De acordo com Ferreira $^{18}$, o trabalho prescrito é definido como tarefas (formais e informais) que operacionalizam uma divisão do trabalho. Diferencia-se do trabalho real, onde a atividade se expressa sob a forma 
Pereira PEC, et al. Inclusão profissional de pessoas com deficiência física. Rev Ter Ocup Univ São Paulo. 2016 maio/ago.;27(2):146-55.

de estratégias operatórias de medição com o contexto de trabalho, que buscam construir um compromisso satisfatório entre as exigências do trabalho prescrito e o bem-estar do trabalhador.

\section{RESULTADOS/DISCUSSÃO}

\section{Perfil Biopsicossocial}

Foram identificadas quatro funções ocupadas pelos nove TCDF, sendo elas: maqueiro (1), auxiliar de recepção e portaria (2), almoxarife de nutrição (1) e técnico de enfermagem (5). Notou-se uma predominância de técnicos de enfermagem, os quais ocupavam diferentes setores e realizavam funções completamente distintas. Por este motivo, neste trabalho, cada função foi descrita e analisada individualmente, considerando as particularidades de cada tarefa e setor.

Com relação aos TCDF, verificou-se o predomínio do sexo feminino (5), faixa etária média de 40 anos, e renda individual variando de um pouco mais que um salário mínimo a um salário e meio e de até três salários mínimos, quando somado a outros moradores de sua residência. Segundo o IBGE (2000), o maior número de PD inseridas no mercado de trabalho está na faixa etária entre 35 e 65 anos, predomínio do sexo masculino, solteiros, e com renda de até 2 salários mínimos.

Partindo para a escolaridade e qualificação profissional, observou-se que todos os trabalhadores possuem nível médio completo e que a maioria (7) possui curso profissionalizante. Notou-se, que embora seja encontrada na literatura a relação dos fatores individuais, econômicos e sociais, outro aspecto que dificulta a inclusão da PD é a falha no processo de formação e qualificação profissional ${ }^{19}$. E ainda que, apesar do amparo legal, as PD estão em desvantagem no mercado de trabalho porque poucos têm instrução e/ou qualificação ${ }^{20}$. Foi possível observar que a população estudada faz parte de uma seleta parcela de PD física que teve acesso à educação e capacitação profissional.

Contudo, mesmo apresentando qualificações profissionais, todos os sujeitos entrevistados possuíam um longo período de afastamento do mercado de trabalho; referiram que a procura também se dava em outras áreas que não estavam relacionadas à sua formação, mas que encontravam diversos tipos de barreiras (físicas, ambientais e sociais). Carreira ${ }^{21}$ detectou em seu estudo que a falta de conhecimento do potencial das $\mathrm{PD}$, entre outras variáveis, consistia num dos grandes motivos que impediam ou dificultavam a contratação dessa população pelas empresas.

Outro ponto a ser destacado é o grau da deficiência. $\mathrm{Na}$ instituição analisada, houve predomínio de PD no nível leve, isto é, não apresentavam comprometimentos funcionais que poderiam interferir no desempenho da tarefa. Martins e $\mathrm{Cabral}^{22}$ trazem que no Brasil há carência de legislação que exija a inclusão de PD mais graves, como pode ser observado em países como a Alemanha, que além das cotas, é exigido que a incapacidade seja no mínimo de $50 \%$, o que ajuda a garantir esta inclusão. Com isto, verifica-se postos de trabalhos ocupados quase exclusivamente por PD leve, e consequente maior exclusão das pessoas com demais deficiências. Esse aspecto pôde ser observado no Quadro 1.

Quadro 1 - Informações sobre as deficiências e tempo de trabalho

\begin{tabular}{|c|c|c|c|c|c|c|}
\hline Sujeito & Tipo de Deficiência & Causa da Deficiência & \begin{tabular}{|l|} 
Tempo da \\
Deficiência \\
\end{tabular} & $\begin{array}{l}\text { Período sem } \\
\text { trabalhar }\end{array}$ & $\begin{array}{l}\text { Tempo de Início das } \\
\text { atividades laborais }\end{array}$ & $\begin{array}{l}\text { Tratamento } \\
\text { Atual } \\
\end{array}$ \\
\hline 1 & Monoparesia & Congênita & mais de 5 anos & 0 & mais de 5 anos & Não \\
\hline 2 & Monoparesia & Congênita & mais de 5 anos & até 12 meses & mais de 5 anos & Não \\
\hline 3 & Amputação & Acidente de carro & mais de 5 anos & $\begin{array}{l}1 \text { a } 2 \text { anos e } 11 \\
\text { meses }\end{array}$ & 1 a 2 anos e 11 meses & Não \\
\hline 4 & Monoplegia & Congênita & mais de 5 anos & $\begin{array}{l}1 \text { a } 2 \text { anos e } 11 \\
\text { meses }\end{array}$ & mais de 5 anos & Não \\
\hline 5 & Monoparesia & Sequela de Poliomielite & mais de 5 anos & até 12 meses & até 12 meses & Não \\
\hline 6 & Monoplegia & $\begin{array}{l}\text { Polineuropatia (com } \\
\text { atrofia muscular) }\end{array}$ & mais de 5 anos & mais de 5 anos & mais de 5 anos & Não \\
\hline 7 & Monoplegia & Sequela de Poliomielite & mais de 5 anos & $\begin{array}{l}1 \text { a } 2 \text { anos e } 11 \\
\text { meses }\end{array}$ & mais de 5 anos & Não \\
\hline 8 & Malformação de Pé & Congênita & mais de 5 anos & 3 a 4 anos & mais de 5 anos & Não \\
\hline 9 & Paraparesia & Poliomielite & mais de 5 anos & mais de 5 anos & mais de 5 anos & Não \\
\hline
\end{tabular}


Pereira PEC, et al. Inclusão profissional de pessoas com deficiência física. Rev Ter Ocup Univ São Paulo. 2016 maio/ago.;27(2):146-55.

\section{Demandas da Tarefa}

Dentre a variedade de postos ocupados pelos TCDF, foi observado que desempenhavam funções completamente distintas, em setores diferentes, sendo eles: Central de material e esterilização, Ambulatório de Oncologia, Banco de leite, Alojamento 2 e Ambulatório da Mulher. Por isto, conforme apresentado no Quadro 2, foram analisadas individualmente.

Identificou-se que na maioria dos postos havia alta demanda de trabalho, caracterizada por carga excessiva de tarefas. Como é possível observar no Quadro 2, referente à técnica de Enfermagem do setor de oncologia, na descrição da função, sua supervisora denomina seu posto como a de uma "tecnocrata" que, segundo ela, "consiste na função de técnica, burocrata e assistente social".

Em se tratando do sistema de rodízios, notou-se que não é uma prática realizada pela maioria dos setores. Podese destacar apenas o setor de materiais e esterilização em que os trabalhadores quinzenalmente trocam de tarefas e o objetivo principal é mudança da postura predominante, "de 15 em 15 dias, eles ficam em uma função que precisa ser realizada sentada e depois trocam para outras que necessitem a posição de pé" (Supervisora do Setor). A organização dos demais setores acontecem no regime de plantões.

Quadro 2 - Demandas e requisitos do posto de trabalho

\begin{tabular}{|c|c|}
\hline Função & Descrição / Requisitos \\
\hline $\begin{array}{l}\text { Maqueiro - Setor de } \\
\text { Triagem Obstétrica }\end{array}$ & $\begin{array}{l}\text { Transporta as pacientes em urgência obstétrica para outros setores, através de cadeira de rodas e macas, } \\
\text { realizando transferência de leitos. } \\
\text { Requisitos: Força física, habilidades interpessoais, habilidade para transporte de pessoas. }\end{array}$ \\
\hline $\begin{array}{l}\text { Almoxarife de } \\
\text { Nutrição }\end{array}$ & $\begin{array}{l}\text { Recebimento, organização e liberação de mercadoria alimentícia. } \\
\text { Requisitos: Ensino Médio, boa noção de matemática, habilidades interpessoais. Treinamento realizado após } \\
\text { contratação }\end{array}$ \\
\hline $\begin{array}{l}\text { Auxiliar de Recepção } \\
\text { e Portaria }\end{array}$ & $\begin{array}{l}\text { Monitoramento das câmeras de segurança } \\
\text { Requisitos: Segundo grau completo, noções de informática. Treinamento de operação das câmeras após a } \\
\text { admissão. }\end{array}$ \\
\hline $\begin{array}{l}\text { Técnico de } \\
\text { Enfermagem- } \\
\text { Alojamento } 2 \\
\text { (pós-parto) }\end{array}$ & $\begin{array}{l}\text { Monitora os sinais vitais das pacientes, realiza curativos, administra medicação e acompanha as pacientes } \\
\text { de alta. } \\
\text { Requisitos: Curso Técnico de Enfermagem, treinamento realizado após admissão no serviço e habilidades } \\
\text { interpessoais. }\end{array}$ \\
\hline $\begin{array}{l}\text { Técnico de } \\
\text { Enfermagem- Banco } \\
\text { de Leite }\end{array}$ & $\begin{array}{l}\text { Atendimento e orientação de aleitamento às mães que chegam ao banco de leite. Pasteurização do leite } \\
\text { humano. } \\
\text { Requisitos: Curso Técnico de Enfermagem, treinamento, cursos realizados pelo serviço relacionado ao } \\
\text { aleitamento e habilidades interpessoais. }\end{array}$ \\
\hline $\begin{array}{l}\text { Técnico de } \\
\text { Enfermagem- Central } \\
\text { de Materiais e } \\
\text { Esterilização }\end{array}$ & $\begin{array}{l}\text { Responsável por enxugar material e verificar se ainda há resíduos de sangue (15 dias nesta função). } \\
\text { Responsável pela preparação das roupas para envio após a esterilização, colocação na autoclave e dispensa } \\
\text { do material ( } 15 \text { dias na função) } \\
\text { Requisitos: Curso Técnico de Enfermagem, agilidade, proatividade, passar por treinamento de um mês após } \\
\text { a admissão. }\end{array}$ \\
\hline $\begin{array}{l}\text { Técnico de } \\
\text { Enfermagem- } \\
\text { Ambulatório da } \\
\text { Mulher }\end{array}$ & $\begin{array}{l}\text { Recebe os pacientes para pré-natal. Atende telefone. Verifica peso e pressão arterial. Organiza as fichas para } \\
\text { atendimento. } \\
\text { Requisitos: Curso Técnico de Informática, noções de informática e habilidades interpessoais. }\end{array}$ \\
\hline $\begin{array}{l}\text { Técnico de } \\
\text { Enfermagem- } \\
\text { Ambulatório de } \\
\text { Oncologia }\end{array}$ & $\begin{array}{l}\text { É responsável pela marcação da primeira vez e volta de quimioterapia, e hormônio-terapia. Orienta os } \\
\text { pacientes aonde vão fazer os exames, resolve junto com os médicos questões de liberação de exames. "Na } \\
\text { verdade, ela é uma 'tecnocrata' técnica, burocrata e assistente social" SIC. } \\
\text { Requisitos: Curso Técnico de Enfermagem e que tenha Experiência na área de Oncologia, deve conhecer o } \\
\text { protocolo de quimioterapia e hormônio-terapia. }\end{array}$ \\
\hline
\end{tabular}


O modelo atual de organização do trabalho impôs um perfil de trabalhador polivalente, que desempenha inúmeras funções. Segundo a Lei, a PD tem direito à jornada especial de trabalho, pode ter horário flexível e reduzido, com proporcionalidade de salário, quando tais procedimentos forem necessários ${ }^{18}$. $\mathrm{O}$ que se pôde observar, na instituição analisada, é que, independente das estratégias realizadas pelo trabalhador, ele consegue atender às demandas da tarefa. Portanto, não há um interesse de ambas as partes que esta medida especial aconteça, pois tanto o empregador não deseja ter o seu funcionário menos tempo no serviço, quanto o trabalhador que já possui uma baixa remuneração, devido ao cargo que ocupa, não deseja ter ainda mais descontos em seu salário.

$\mathrm{O}$ fator Tempo/velocidade não determina grande parte das tarefas realizadas, sendo observado apenas nas funções de maqueiro, pois se encontra na urgência obstétrica, e técnico de Enfermagem do setor de materiais e esterilização, pois trabalham com o prazo de $72 \mathrm{~h}$ para entrega de cada material. Uma função que pode ser destacada, apesar de não ter este fator relacionado com sua tarefa, é a de técnico de Enfermagem do ambulatório de oncologia. Segundo sua supervisora, apesar de ser diarista ( $7 \mathrm{~h}$ às $17 \mathrm{~h})$, a trabalhadora realiza horas extras frequentemente, por necessidades do serviço.

É possível observar que das Habilidades necessárias para as funções, exceto a função de maqueiro, todas as outras exigiam um grau de escolaridade e capacitação profissional. Segundo a OIT $^{23}$, antes de ser instituída a obrigatoriedade de contratação de $\mathrm{PD}$, raras eram as empresas que as empregavam. Portanto, a elas não foram dadas oportunidades para terem em seu currículo experiência profissional. Assim, de uma forma geral, delas não se deve exigir experiência, porém os achados revelaram o contrário.

Ao mesmo tempo, percebe-se o investimento da instituição em palestras e cursos periódicos como uma forma de incentivo e aperfeiçoamento da função desempenhada. Fato este que é pontuado pela $\mathrm{OIT}^{23}$, recomendando que quando a experiência for efetivamente necessária ao desempenho da função, a empresa deve oportunizar que a pessoa adquira internamente as habilidades, a postura de trabalho e os conhecimentos exigidos para o exercício de certos cargos.

Apesar de reconhecido o incentivo à capacitação, na maioria dos casos não houve ajuste especial e nem adaptações para a execução das tarefas. As funções eram desempenhadas de forma satisfatória no ponto de vista do supervisor e do trabalhador. O único caso onde se realizou ajuste foi o da Técnica em Enfermagem que estava alocada no setor de materiais e esterilização, local caracterizado por acúmulo excessivo de água em algumas áreas do piso, devido a limpeza dos materiais. Essa trabalhadora, por apresentar deformidade no membro inferior esquerdo (MIE), não conseguia fazer uso de calçados apropriados e por isto não fazia rodízio nos locais que apresentavam acúmulo de água no piso.

O último ponto a ser questionado tratou da questão da postura dos supervisores a respeito da inclusão destes $e$ de novos TCDF. Observou-se que todos mostraram não ter nenhuma objeção quanto à existência destes trabalhadores no setor, através de discursos como: "Não vejo problemas, acho que são até mais dedicados que os outros", "No caso dela não tem problema, nunca faltou e nem reclamou de nada", "Posso ser sincera? Para mim ela vale por duas". Ao analisar as descrições das funções, e considerar as demandas requeridas e o fato de que cada funcionário consegue atendêlas, é possível compreender a natureza de todos estes relatos.

Contudo, ao serem questionados quanto à entrada de novos trabalhadores, muitos demonstram de forma clara, a limitação do setor em recebê-los, sendo agravada pelo fato do desconhecimento da capacidade funcional destas pessoas, e acima de tudo a deficiência de um olhar voltado para o indivíduo e não para a incapacidade: "Poderia vir qualquer deficiente que não fosse físico", "Pessoas com limitações de locomoção não poderiam trabalhar aqui", "Quanto a novos TCD... o ideal é que não tenha, pois um indivíduo com um grau de deficiência elevado estará exposto a um alto risco de acidentes".

Contudo, a Organização Mundial de Saúde preconiza que uma deficiência na estrutura e/ou função do corpo não é determinante para que o indivíduo apresente dificuldades na execução do trabalho, pois a condição de funcionalidade depende ainda do contexto pessoal e ambiental, no qual o sujeito está inserido ${ }^{1}$. Pode-se destacar também, a falta de conhecimento por parte dos supervisores a respeito da inclusão de trabalhadores, dos recursos tecnológicos que auxiliam nesse processo, visto que a todo o momento os postos eram restritos a determinados tipos de deficiência.

Segundo Simonelli ${ }^{17}$, a inclusão deve ser entendida como a preparação social e técnica das PD para o trabalho, adequação do local de trabalho e ambiente, bem como o acompanhamento psicossocial e do desenvolvimento técnico das mesmas.

\section{Componentes Requeridos para a Tarefa}

O Quadro 3 apresenta as posturas predominantes de todos os TCDF nas tarefas desempenhadas, bem como a realização de trocas posturais, e dificuldade mediante $o$ processo de trabalho, referidos pelos trabalhadores. 
Pôde-se observar que cinco das funções descritas exigem a postura de pé e movimento/deslocamento, onde há uma exigência mais elevada dos componentes sensório-motores. Para os trabalhadores como maqueiro e um dos auxiliares de recepção e portaria, que possuem limitações nos membros superiores, estas posturas acabam não interferindo no processo de trabalho. Contudo o outro auxiliar de recepção e portaria, que possui limitações nos membros inferiores (MMII), e tem por descrição da função as mesmas tarefas que o outro auxiliar, refere que sua postura predominante é sentada, e que por isto não apresenta dificuldades no processo de trabalho.

Quadro 3 - Relação entre a tarefa e as posturas adotadas

\begin{tabular}{|c|l|l|l|l|}
\hline Sujeito & Função & Postura predominante & $\begin{array}{l}\text { Realiza trocas } \\
\text { posturais }\end{array}$ & $\begin{array}{l}\text { Dificuldade no processo } \\
\text { de Trabalho }\end{array}$ \\
\hline 1 & Maqueiro & Movimento/ Deslocamento & Sim & Não \\
\hline 2 & Almoxarife de Nutrição & Movimento/ Deslocamento & Sim & Não \\
\hline 3 & Auxiliar de Recepção e Portaria & Sentado & Sim & Não \\
\hline 4 & Técnica de Enfermagem- alojamento 2 & Movimento/ Deslocamento & Sim & Não \\
\hline 5 & Técnica de Enfermagem- Banco de leite & Movimento/ Deslocamento & Sim & Não \\
\hline 6 & $\begin{array}{l}\text { Técnica de Enfermagem-Central } \\
\text { de Material e Esterilização }\end{array}$ & Em Pé & Com dificuldade & Não \\
\hline 7 & $\begin{array}{l}\text { Técnica de Enfermagem- Ambulatório } \\
\text { da Mulher }\end{array}$ & Sentado & Sim & Não \\
\hline 8 & Auxiliar Recepção e Portaria & Sentado & Sim & Não \\
\hline 9 & $\begin{array}{l}\text { Técnica de Enfermagem- Ambulatório } \\
\text { de Oncologia }\end{array}$ & Sentado & Sim & Sim \\
\hline
\end{tabular}

Tabela 4A - Relação entre os componentes requeridos pela tarefa e as funções exercidas pelos TCDF

\begin{tabular}{|c|c|c|c|c|c|c|c|c|c|c|c|c|}
\hline & \multicolumn{3}{|c|}{ Maqueiro } & \multicolumn{3}{|c|}{ Almoxarife de Nutrição } & \multicolumn{3}{|c|}{ Aux. Recepção e Portaria } & \multicolumn{3}{|c|}{ Téc. Enfermagem } \\
\hline & Sim & Não & Raramente & Sim & Não & Raramente & Sim & Não & Raramente & Sim & Não & Raramente \\
\hline $\begin{array}{l}\text { Atividade } \\
\text { Binamal }\end{array}$ & $\mathrm{X}$ & & & $\mathrm{X}$ & & & $\mathrm{X}$ & & & $\mathrm{X}$ & & \\
\hline $\begin{array}{l}\text { Coord. Motora } \\
\text { Fina }\end{array}$ & & & $\mathrm{X}$ & & & $\mathrm{X}$ & $\mathrm{X}$ & & $X$ & $\mathrm{X}$ & & \\
\hline $\begin{array}{l}\text { Coord. } \\
\text { Viso-motora }\end{array}$ & $\mathrm{X}$ & & & $\mathrm{X}$ & & & $\mathrm{X}$ & & & $\mathrm{X}$ & & \\
\hline $\begin{array}{l}\text { Levantamento } \\
\text { de Peso }\end{array}$ & $\mathrm{X}$ & & & $\mathrm{X}$ & & & $\mathrm{X}$ & $\mathrm{X}$ & & $\mathrm{X}$ & $\mathrm{X}$ & \\
\hline $\begin{array}{l}\text { Deslocamento } \\
\text { de Peso }\end{array}$ & $\mathrm{X}$ & & & $\mathrm{X}$ & & & $\mathrm{X}$ & $\mathrm{X}$ & & & $\mathrm{X}$ & \\
\hline $\begin{array}{l}\text { Coord. Global } \\
\text { Dissociada } \\
\end{array}$ & $\mathrm{X}$ & & & $\mathrm{X}$ & & & $\mathrm{X}$ & $\mathrm{X}$ & & $\mathrm{X}$ & $\mathrm{X}$ & \\
\hline $\begin{array}{l}\text { Equilíbrio } \\
\text { Estático }\end{array}$ & & $\mathrm{X}$ & & & $X$ & & & $X$ & & $\mathrm{X}$ & $\mathrm{X}$ & \\
\hline $\begin{array}{l}\text { Equilíbrio } \\
\text { Dinâmico }\end{array}$ & $\mathrm{X}$ & & & $\mathrm{X}$ & & & & $\mathrm{X}$ & & $\mathrm{X}$ & $\mathrm{X}$ & \\
\hline Agilidade & $\mathrm{X}$ & & & $\mathrm{X}$ & & & $\mathrm{X}$ & & & $\mathrm{X}$ & $\mathrm{X}$ & \\
\hline $\begin{array}{l}\text { Diferencia } \\
\text { Sons }\end{array}$ & & $\mathrm{X}$ & & & $\mathrm{X}$ & & $\mathrm{X}$ & & & $\mathrm{X}$ & $\mathrm{X}$ & \\
\hline $\begin{array}{l}\text { Distinguir } \\
\text { Intensidade }\end{array}$ & & $\mathrm{X}$ & & & $\mathrm{X}$ & & $\mathrm{X}$ & $\mathrm{X}$ & & $\mathrm{X}$ & $\mathrm{X}$ & \\
\hline
\end{tabular}


Pereira PEC, et al. Inclusão profissional de pessoas com deficiência física. Rev Ter Ocup Univ São Paulo. 2016 maio/ago.;27(2):146-55.

Tabela 4B - Relação entre os componentes requeridos pela tarefa e as funções exercidas pelos TCDF

\begin{tabular}{l|c|c|c|c|c|c|c|c|c|c|c|c}
\hline & \multicolumn{3}{|c|}{ Maqueiro } & \multicolumn{3}{c|}{ Almoxarife de Nutrição } & \multicolumn{3}{c}{$\begin{array}{c}\text { Aux. Recepção e } \\
\text { Portaria }\end{array}$} & \multicolumn{3}{c}{ Téc. Enfermagem } \\
\hline & Mín. & Mod. & Máx. & Mín. & Mod. & Máx. & Mín. & Mod. & Máx. & Mín. & Mod. & Máx. \\
\hline $\begin{array}{l}\text { Raciocínio } \\
\text { Exigido }\end{array}$ & & $\mathrm{X}$ & & & & $\mathrm{X}$ & $\mathrm{X}$ & & $\mathrm{X}$ & & $\mathrm{X}$ & $\mathrm{X}$ \\
\hline $\begin{array}{l}\text { Cognição } \\
\text { Exigida }\end{array}$ & & & $\mathrm{X}$ & & & $\mathrm{X}$ & $\mathrm{X}$ & $\mathrm{X}$ & $\mathrm{X}$ & $\mathrm{X}$ & $\mathrm{X}$ & $\mathrm{X}$ \\
\hline $\begin{array}{l}\text { Resolução de } \\
\begin{array}{l}\text { Problemas e } \\
\text { Tomadas }\end{array}\end{array}$ & & $\mathrm{X}$ & & & & $\mathrm{X}$ & $\mathrm{X}$ & $\mathrm{X}$ & $\mathrm{X}$ & & $\mathrm{X}$ & $\mathrm{X}$ \\
\hline $\begin{array}{l}\text { Acuidade } \\
\text { Visual }\end{array}$ & & & $\mathrm{X}$ & & & $\mathrm{X}$ & $\mathrm{X}$ & & $\mathrm{X}$ & & $\mathrm{X}$ & $\mathrm{X}$ \\
\hline $\begin{array}{l}\text { Acuidade } \\
\text { Auditiva }\end{array}$ & & & $\mathrm{X}$ & & $\mathrm{X}$ & & $\mathrm{X}$ & $\mathrm{X}$ & $\mathrm{X}$ & $\mathrm{X}$ & & $\mathrm{X}$ \\
\hline $\begin{array}{l}\text { Atenção } \\
\text { Exigida }\end{array}$ & & & $\mathrm{X}$ & & & $\mathrm{X}$ & $\mathrm{X}$ & & $\mathrm{X}$ & & & $\mathrm{X}$ \\
\hline $\begin{array}{l}\text { Importância do } \\
\text { Trabalho }\end{array}$ & & & $\mathrm{X}$ & & & $\mathrm{X}$ & $\mathrm{X}$ & & $\mathrm{X}$ & & & $\mathrm{X}$ \\
\hline $\begin{array}{l}\text { Responsabili- } \\
\text { dade }\end{array}$ & & & $\mathrm{X}$ & & & $\mathrm{X}$ & $\mathrm{X}$ & & $\mathrm{X}$ & & & $\mathrm{X}$ \\
\hline $\begin{array}{l}\text { Relações } \\
\text { Interpessoais }\end{array}$ & & & $\mathrm{X}$ & & & $\mathrm{X}$ & $\mathrm{X}$ & $\mathrm{X}$ & $\mathrm{X}$ & & $\mathrm{X}$ & $\mathrm{X}$ \\
\hline
\end{tabular}

Mín = Mínimo $/$ Mod $=$ Moderado $/$ Máx = Máximo

Já a Técnica de Enfermagem do Ambulatório de Oncologia relata passar a maior parte do tempo sentada; diz conseguir realizar as demais trocas posturais, mas que sente dificuldade no processo de trabalho. Em entrevista, refere não suportar passar longos períodos de pé, e que quando há necessidade de dar suporte no salão, onde há uma exigência desta postura, chega a sentir muitas dores e desconforto.

As Tabelas 4A e 4B relacionam os postos de trabalho com os componentes requeridos para cada função. A partir do questionário de funcionalidade, foi possível observar que quase todos os casos, por se tratarem de níveis de deficiência leve, não interferiam na função desempenhada, por exemplo, trabalhadores que possuíam limitações nos MMII, mas que em suas tarefas eram exigidas predominantemente atividades bimanuais. Pôde-se destacar a diferença entre as funções exercidas pelos técnicos de enfermagem, que apresentam demandas completamente distintas, mas que possuem as mesmas exigências em relação aos componentes, apresentando apenas pequenas variações.
Conforme verificado nos dados e de acordo com a literatura, percebe-se que uma dificuldade elevada das empresas reside no desconhecimento a respeito da questão da deficiência, o que as leva em muitos casos a contratar pessoas com deficiências leves, desconhecendo suas capacidades, além das limitações. Essa situação gera medo, insegurança, preconceito e pode inviabilizar o processo de inclusão.

Este estudo identificou um fato comum a todas as funções, que consiste na associação de algumas tarefas com os tipos de deficiência, este fato também está relacionado aos novos TCD. De acordo com o Ministério do Trabalho e Emprego - MTE ${ }^{6}$, tal correlação é restritiva, pois não permite vislumbrar as diversas potencialidades que as PD podem desenvolver no trabalho. Assim, antes de afirmar que uma PD não tem condições, é preciso dar a ela oportunidade de revelar suas reais potencialidades para desempenhar as funções. Para tanto, é imprescindível a realização de avaliação de desempenho e funcionalidade para orientação do trabalhador e do empregador quanto às demandas reais do trabalho e ajustes às reais capacidades da pessoa com deficiência. 
Pereira PEC, et al. Inclusão profissional de pessoas com deficiência física. Rev Ter Ocup Univ São Paulo. 2016 maio/ago.;27(2):146-55.

\section{CONSIDERAÇÕES FINAIS}

Diante do que é preconizado pela Lei de Cotas, foi identificado que este serviço, embora apresentando um quantitativo de TCDF reduzido quando comparado ao total de funcionários, não apresentou problemas em relação à colocação dos trabalhadores, que fizeram parte do estudo, em seus respectivos postos. Contudo, percebeu-se, que o serviço tem selecionado as pessoas para se adequarem aos postos, ao invés de ajustarem os postos e ambientes de trabalho às habilidades dos trabalhadores para executarem as tarefas.

A descrição do perfil epidemiológico e biopsicossocial dos TCDF desta instituição, a partir dos relatos apresentados, mostrou-se relevante como parte inicial do processo de avaliação da capacidade funcional destes indivíduos. Contudo, para a execução de mudanças efetivas, faz-se necessário um estudo mais aprofundado com a observação do trabalho real destes funcionários, observando questões de Ergonomia, Acessibilidade e da própria organização do trabalho, evitando, que essas pessoas estejam expostas a riscos de acidentes ou que com o tempo possam apresentar doenças ocupacionais e agravamento da deficiência.

\section{REFERÊNCIAS}

1. Mângia EF, Muramoto MT, Lancman S. Classificação Internacional de Funcionalidade e Incapacidade e Saúde (CIF): processo de elaboração e debate sobre a questão da incapacidade. Rev Ter Ocup Univ São Paulo. 2008;19(2):12130. DOI: $14037 / 15855$.

2. Brasil. Lei $\mathrm{n}^{\circ} 13.146$, de 6 de julho de 2015. Lei Brasileira de Inclusão da Pessoa com Deficiência. Disponível em: http:// www.planalto.gov.br/ccivil_03/_Ato2015-2018/2015/Lei/ L13146.htm/.

3. Instituto Brasileiro de Geografia e Estatística (IBGE). Censo 2010. Disponível em http://censo2010.ibge.gov.br/.

4. Brasil. Decreto $n^{0}$ 3.298, de 20 de dezembro de 1999. Disponível em: http://www.planalto.gov.br/ccivil_03/ decreto/d3298.htm.

5. Brasil. Secretaria de Direitos Humanos. Decreto $\mathrm{n}^{0} 7.612$, de 17 de novembro de 2011. Disponível em: http://www.planalto.gov. br/CCIVIL_03/_Ato2011-2014/2011/Decreto/D7612.htm/.

6. Brasil. Ministério do Trabalho e do Emprego. A inclusão da pessoa com deficiência no mercado de trabalho. 2ed. $100 \mathrm{p}$. Brasília, 2007.
Os dados apontaram uma tendência da instituição a associar a seleção das tarefas a serem executadas ao tipo de deficiência apresentada. Diante disso, propõe-se que a seleção dos postos seja realizada baseada nas habilidades reais das pessoas para o desempenho das tarefas, apesar das deficiências. Destaca-se também a necessidade de mudança cultural na visão dos gestores sobre a real capacidade das PD, uma alternativa seria a realização de programas de conscientização e esclarecimento, com profissionais habilitados, como o terapeuta ocupacional, possibilitando com isso, mais oportunidades de trabalho a PD.

Este estudo possibilitou contribuir do ponto de vista científico e prático à Terapia Ocupacional, voltando seu olhar para a atividade laboral de pessoas com deficiência física, bem como permitiu estimular a reflexão das ações da profissão em torno deste público. Além disso, disponibilizou-se à instituição em questão a correspondência da capacidade funcional às demandas dos postos de trabalho de seus funcionários com deficiência, a fim de construir um conhecimento inicial para futuras contratações e realocação de postos, quando necessário.

7. Brasil. Secretaria Especial dos Direitos Humanos da Presidência da República-SDH. Ministério do Planejamento, Orçamento e Gestão - MP. Ministério da Previdência Social - MPS; Presidência da República - PR. Lei complementar $\mathrm{n}^{\circ}$ 142, de 8 de maio de 2013. Disponível em: http://www. planalto.gov.br/ccivil_03/leis/LCP/Lcp142.htm.

8. Brasil. Ministério da Saúde. Manual de legislação em saúde da pessoa portadora de deficiência. secretaria de assistência à saúde. Brasília: Ministério da Saúde; 2003.

9. Dejours C. Addendum: da psicopatologia à psicodinâmica do trabalho. In: Lancman S, Sznelwar LI, organizadores. Christophe Dejours: da psicopatologia à psicodinâmica do trabalho. Rio de Janeiro: Editora Fiocruz; 2004. p.47-104.

10. Di Napoli JP. Acessibilidade versus segurança para pessoas portadoras de deficiências: estudo de caso em uma refinaria de petróleo. In: XIII Congresso Brasileiro de Ergonomia, II Fórum Brasileiro de Ergonomia, I Congresso Brasileiro de Iniciação Científica em Ergonomia - ABERGO Jovem, 2004, Fortaleza, CE. Anais. Fortaleza, CE; 2004. 
11. Conselho Federal de Fisioterapia e Terapia Ocupacional (COFFITO). Lista de procedimentos da Terapia Ocupacional completa. São Paulo; 2007. Disponível em: http://www. coffito.org.br/site/index.php/terapia-ocupacional/lpto.html.

12. Conselho Federal de Fisioterapia e Terapia Ocupacional (COFFITO). Resolução no 459, de 20 de novembro de 2015 . Disponível em: http://www.coffito.org.br/site/index.php/home/ resolucoes-coffito/966-resolucao-n-459-de-20-de-novembro-de2015-dispoe-sobre-as-competencias-do-terapeuta-ocupacionalna-saude-do-trabalhador-atuando-em-programas-de-estrategiasinclusivas-de-prevencao-protecao-e-recuperacao-da-saude.html.

13. Lancman S. Saúde, trabalho e terapia ocupacional. São Paulo: Roca; 2004.

14. Rodrigues WC. Metodologia científica. Fundação de apoio à escola técnica do estado do Rio de Janeiro. Paracambi, RJ; 2007. Disponível em: http://professor.ucg.br/siteDocente/ admin/arquivosUpload/3922/material/Willian\%20Costa\%20 Rodrigues_metodologia_cientifica.pdf.

15. Minayo MCS, Sanche O. Quantitativo-qualitativo: oposição ou complementaridade? Cad Saúde Pública. 1993;9(3):237-48. DOI: http://dx.doi.org/10.1590/S0102311X1993000300002.

16. Bardin L. Análise de conteúdo. Lisboa: Edições 70; 2015.

17. Simonelli AP, Camarotto JA. As políticas brasileiras e internacionais de incentivo ao trabalho de pessoas com deficiência: uma reflexão. Cad Ter Ocup UFSCar, São Carlos. 2011;19(3):333-42. DOI: 10.4322/cto.2011.006.

18. Ferreira MC. Bem-estar: equilíbrio entre a cultura do trabalho prescrito e a cultura do trabalho real. In: Tamayo A, organizador. Cultura e saúde nas organizações. São Paulo: Artmed; 2004. p.181-207.

19. Nunes LRO, et al. Pesquisa em educação especial na pósgraduação. Rio de Janeiro: Sette Letras; 1998.

20. Philereno DC, Sartor N, Rotta C, Krewer EJ, Oliveira SM. Qualificação das pessoas com deficiência para o mercado de trabalho: um estudo de caso em Caxias do Sul - RS. Est. Debate, Lajeado. 2015;22(1):160-79. Disponível em: http:// www.univates.br/revistas/index.php/es;tudoedebate/article/ viewFile/1312/740.

21. Carreira D. A integração da pessoa deficiente no mercado de trabalho. São Paulo: Fundação Getúlio Vargas; 1996.

22. Martins LB, Cabral AKPS. Ergonomics and the inclusion of disabled people in the Brazilian job market. Work (Reading, MA). 2012;41:5493-9. DOI: 10.3233/WOR-2012-08635493.

23. Organização Internacional do Trabalho (OIT). Adaptação de ocupações e o emprego do portador de deficiência. Brasília: CORDE; 1997.

Recebido em: 30.10 .15

Aceito em: 13.01.16 